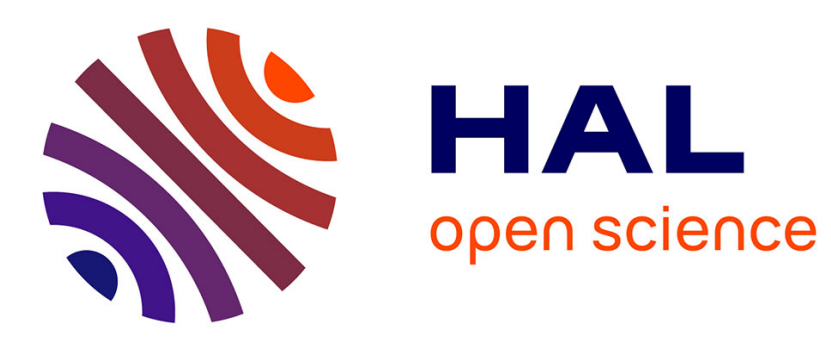

\title{
Editorial overview: Neuroecology of insects: when ultimate and proximate explanations unite
}

\author{
Basil El Jundi, Antoine Wystrach
}

\section{To cite this version:}

Basil El Jundi, Antoine Wystrach. Editorial overview: Neuroecology of insects: when ultimate and proximate explanations unite. Current Opinion in Insect Science, 2020, 42, pp.iii-v. 10.1016/j.cois.2020.11.013 . hal-03431290

\section{HAL Id: hal-03431290 \\ https://hal.science/hal-03431290}

Submitted on 17 Dec 2021

HAL is a multi-disciplinary open access archive for the deposit and dissemination of scientific research documents, whether they are published or not. The documents may come from teaching and research institutions in France or abroad, or from public or private research centers.
L'archive ouverte pluridisciplinaire HAL, est destinée au dépôt et à la diffusion de documents scientifiques de niveau recherche, publiés ou non, émanant des établissements d'enseignement et de recherche français ou étrangers, des laboratoires publics ou privés. 


\title{
Neuroecology of insects: when ultimate and proximate explanations unite
}

\author{
Guest Editors: Basil el Jundi ${ }^{1}$ and Antoine Wystrach ${ }^{2}$ \\ ${ }^{1}$ Zoology II, Biocenter, University of Würzburg, Würzburg, Germany \\ ${ }^{2}$ Research Centre on Animal Cognition, Centre for Integrative Biology, CRNS, University of Toulouse, Toulouse, \\ France
}

Neuroscience and ecology are traditionally two very different schools of research. Still today, each discipline is arguably represented by people with directly opposed points of view and daily routines. Anybody can easily picture the neuroscientist in a white coat dissecting and exploring the brain substrate in the lab, or the field ecologist in rubber boots outdoors, claiming her/his holistic view of nature. Certainly, some truth is enshrined in these depictions; however, the more the neuroscientist explores the general principles of the brain in the lab, the more she/he needs to understand the ecologist's point of view (and vice versa). This is because the animal's habitat will inevitably influence the neuroarchitecture and activity of a brain throughout evolution; resulting in a neural machinery that both acts upon, and is crafted by, the animal's environment and goals. Today, we see a growing community of scientists that combine both neurobiology and ecology in their research. The common points that bind these scientists are clear: the theory of evolution, behaviour, and a comparative approach. Together, this combination forms what can be called 'Neuroecology' [1].

The study of insects, with their wealth of species adequate to both lab and field studies, has proven to be a fertile ground for neuroecology. These tiny animals execute a remarkably large repertoire of behaviours in any kind of ecological habitat, proving that, despite the apparently conserved core design shared by all insects' brains, selective pressures can tweak these brains in ways that fit drastically different lifestyles, from flying visual predators to crawling olfaction-guided plant eaters [2]. How does the insect brain conserve such a core design while simultaneously enabling the rapid evolution of diverse behaviours? How does the insect brain deal with rapid changes in the environment, such as the changes induced by humans? The aim of this issue is to provide several mini-reviews on the neuroecology of insects as diverse as bees, wasps, ants, dragonflies, and butterflies, to grasp the state of the art in the field and demonstrate the power of this integrative approach.

In the first article, Renou and Anton review how olfactory information is processed in the insect brain - from the input stages in the antennae to the processing of information in the mushroom bodies [3,4] but do so in the context of the species ecology. The processing of olfactory information is the most investigated, and arguably the predominant sensory modality in insects. In addition, the 
authors review our knowledge of how olfactory and visual information is combined in the brain and how pesticides and light pollution affect the coding of olfactory information.

In the second review, Haverkamp and Hans Smid exploit the long-term relationship between parasitoid wasps and their larval host [5] to shed light on their respective neurophysiology. It turns out that both parties have evolved remarkably fine-tuned adaptations dedicated to beat the other. Thus, mechanosensory receptors of the prey are tuned to the wing beat frequency of the predator, while specific neural pathways in the predator's brain enable the presence of host cues to act as appetitive reinforcer for memorising the current surroundings cues. The authors disentangle the adaptations based on the sequence of events happening in a natural encounter, from the distant search for the host to the final contact. The authors also show that the dynamic of learning involved at all stages is equally tuned to the other party's ecology and these differences can be traced right back to neurophysiological peculiarities observed in their respective brains. A co-evolutionary lens was clearly the right way to approach it!

In addition to olfaction, visual information, such as colour information, is crucial for pollinators, such as butterflies, to recognize their host plants [6]. One of these butterflies, the swallowtail butterfly has been studied extensively in recent years both behaviourally and neurophysiologically. In their article, Kinoshita and Stewart review and compare the visual systems of these butterflies to those of other pollinators. The results give insight into how butterflies use visual information for flower detection. In contrast to many other insects, the swallowtail butterfly uses four photoreceptors (uv, blue, green, red) for colour vision. In addition to colour, brightness and polarization vision are used to learn the visual qualities of their food source unambiguously, in a complex environment.

Neuroscience needs to diversify its model species [7], so why not butterflies? Butterflies are ideal candidates for study by neuroecologists, but are yet underutilised. This is the point made by Couto, Wainwright, Morris and Montgomery. Their review explains that butterflies have gone through a late evolutionary radiation, leading to an abundance of species showing various behavioural innovations adapted to specific ecological tasks. Despite the relatively recent origin of this radiation, butterflies show quite different sensory systems as well as brain morphology, which can thus be related precisely to each species' specific ecology. What's more, the authors argue that the number of genomic and neurobiological tools available in butterflies are growing. All the ingredients are in place to offer a rare opportunity to compare brain circuits in the light of ecology.

Baird, Tichit and Guiraud, also embarked on a comparative study, but this time across the flight styles of bees. Flight control has traditionally been studied in honeybees and bumblebees under 
laboratory conditions [8]. These hymenopterans have been used to derive the general strategies by which insects use the pattern of motion on the bee's retina, termed optic flow, to stabilize their flights, avoid collisions with objects in their environment, and execute their landings. The authors review the recent studies that have focused on other species of bee and found differences in the use of optic flow information for flight control that correlate well with of the animal's the visual ecology. Notably, we now understand how and why some species perform kamikaze landings. The authors discuss the eye architecture of the different bee species, likely the key structure that allows the bees to fine-tune their natural navigational tasks.

Can we find differences in brain anatomy between insects that exhibit different ecological lifestyles, such as nocturnal vs. diurnal, migratory vs. non-migratory, or eusocial vs. solitary? Bouchebti and Arganda review, in detail, how the neural substrate correlates with the animal's ecology and how the brain is adapted to certain modus vivendi. The authors focus in particular on the first integration centres, the optic and antennal lobes, and point out that where strong differences in the neuroanatomy are found in these regions, they relate to differing ecologies [9.10]. While many studies have focused on the study of the sensory input stages in the brain, higher brain centres, such as the mushroom bodies and the central complex, have received little attention but might well be the focus of future studies, as technical advances allow a more accurate analysis of brain morphology.

Modern neurobiological tools yield a massive amount of data ... however, focusing on the neural level only may not be a good strategy [11]. Le Moël and Wystrach show convincingly that the field of insect navigation benefited a lot from combining neural data with ecology, and modelling. This field has been blessed with a strong ethological and modelling history, which led neuroscientists and computational scientists to investigate the 'navigational brain' as a dynamical system viewed through ecologically relevant goggles. From this perspective, behaviour is not a direct consequence of brain activity, but emerge from complex interactions between the brain, body and environment. The authors demonstrate why such considerations are key to understand the mechanisms of behaviour.

The final chapter of this issue focuses on a stunning animal. Dragonflies are not only fascinating because they belong to the most ancient insect families on our planet and have large compound eyes that are equipped with up to 30,000 ommatidia but also because of their prey-catching behaviour. However, what makes dragonflies such efficient predators? What kind of strategy do dragonflies employ to catch their prey and how is the neural substrate adapted to reliably track a prey during 
flight? Lancer et al. summarize our recent knowledge on the adaptation of the visual system and the behavioural strategies that allows these animals to catch their prey so accurately. Based on recent studies, adaptations of the dragonfly's compound eyes and the underlying neuronal network in the brain, combined with the ability to execute formidable manoeuvres during flight allows these animals to reach extremely high capture rates within complex environments [Olberg et al. 2017].

We are very grateful to all authors and reviewers for their contribution to this special issue. We hope it will inspire future works and young scientists in undertaking an approach that combine neuroscience with ecology to shed light on the richness of animal behaviours.

\section{References}

1. Sherry DF: Neuroecology. Annu Rev Psychol 2005, 57:167-197.

2. Strausfeld NJ: Arthropod Brains: Evolution, Functional Elegance, and Historical Significance. Harvard University Press; 2012.

3. Martin JM, Beyerlein A, Dacks AM, Reisenman CE, Riffell JA, Lei H, Hildebrand JG: The neurobiology of insect olfaction: Sensory processing in a comparative context. Prog Neurobiol 2011, 95:427-447.

4. Hansson BS, Stensmeyr MC: Evolution of insect Olfaction. Neuron 2011, 72:698-711.

5. Hoedjes KM, Kruidhof HM, Huigens ME, Dicke M, Vet LEM, Smid HM: Natural variation in learning rate and memory dynamics in parasitoid wasps: opportunities for converging ecology and neuroscience. Proc R Soc B: Biol Sci 2011, 278: 889-897.

6. Van der Kooi CJ, Stavenga DG, Arikawa K, Belušič G, Kelber A: Evolution of insect color vision: from spectral sensitivity to visual ecology. Ann Rev Entomol 2021, 66:23.1-23.28.

7. Hale ME: Toward diversification of species models in neuroscience. Brain Behav Evolut 2019, 93:166-168.

8. Srinivasan MV, Zhang SW, Chahl JS, Barth E, Venkatesh S: How honeybees make grazing landings on flat surfaces. Biol Cybern 2000, 83:171-183.

9. Heinze S, Florman J, Asokaraj S, el Jundi B, Reppert SM: Anatomical basis of sun compass navigation II: the neuronal composition of the central complex of the monarch butterfly. J Comp Neurol 2013, 521:267-98.

10. Stoeckl A, Heinze S, Charalabidis A, el Jundi B, Warrant E, Kelber A: A trade-off between vision and olfaction: Brain volume predicts the importance of sensory cues in hawkmoth foraging. Sci Rep 2016, 17:626041 
11. Krakauer, JW, Ghazanfar AA, Gomez-Marin A, MacIver MA, Poeppel D : Neuroscience needs behavior: correcting a reductionist bias. Neuron 2017, 93:480-490.

12. Olberg RM, Worthington AH, Venator KR: Prey pursuit and interception in dragonflies. $J$ Comp Physiol A 2000, 186:155-162.

\section{Mini CV}

Antoine Wystrach is a group leader at the University of Toulouse. Trained as a biologist, he spent a $\mathrm{PhD}$ in the Australian's outback studying ant navigation, then a few years in the UK as a postdoc modelling insects' brain and behaviour and eventually obtained a research position as CNRS researcher in Toulouse, France. Antoine now studies ant navigation in both the lab and the field, using fancy tools such as virtual reality, neural models and 3D worlds... or sometimes just using his hands to move an ant from A to B.

Basil el Jundi is a group leader at the University of Würzburg. After a PhD on the sky compass network in the brain of the desert locust at the University of Marburg, he studied the behavioural and neural mechanisms of the orientation compass of ball rolling dung beetles as a postdoc at the Lund University. His group is currently using the monarch butterfly Danaus plexippus to behaviourally and neurophysiologically study the insect migratory compass. 